\title{
CSF upward motion is crucial for ETV success
}

Hans Christoph Ludwig (orcid.org/0000-0001-8744-9510) ${ }^{1}$, Steffi Dreha-Kulaczewski

(https://orcid.org/0000-0003-4951-3176) ${ }^{2}$, Hans Christoph Bock (https://orcid.org/0000$\underline{0002-6656-6053})^{1}$

1. Department of Neurosurgery, Division of Pediatric Neurosurgery, University Medical Center Göttingen, Robert-Koch-Str. 40, 37075 Göttingen, Germany

2. Department of Pediatrics and Adolescent Medicine, Division of Pediatric Neurology, University Medical Center Göttingen, Robert-Koch-Str. 40, 37075 Göttingen, Germany

Key words: Neuroendoscopy, ETV, Hydrocephalus, ETVSS, T2 flow void, Real-time MRI, Inspiration

\section{Abstract}

Purpose: ETV is indicated for treating obstructions of major CSF pathways. The outcome evaluation often yields success rates of only $+-70 \%$ for shunt independency. Hence, compromised CSF absorption seems to occur more often than expected. We searched for parameters suitable to assess the involved CSF dynamics.

Material and Methods: This was a prospective study in 58 paediatric patients ( $7.7 \mathrm{yrs}$. mean age) between 2000 and 2020 with aqueductal stenosis (11/58), obstruction of the aqueduct due to tumor growth (22/58), and connatal hydrocephalus (9/58). The average follow-up 
interval was 4.7 years. Head circumferences, Evans- and fronto-occipital horn ratios before and 3 months after ETV were obtained as Delta-indices. Furthermore ETV success score (ETVSS), the patency of the aqueduct pre- and postoperatively as well as of the stoma were assessed by flow void signs on MRI. Evaluation on MRI also included the shape of the floor of the $3^{\text {rd }}$ ventricle and whether or not the septum pellucidum showed signs of perforation. Four patients were analysed pre- and postoperatively via real-time MRI. At least the educational status regarding protected or unprotected education was analyzed.

\section{Results:}

The prevalence of a bowing of the floor of the $3^{\text {rd }}$ ventricle was $72 \%$, and the ETVSS was $71.0 \%$. In 26 children a septal perforations or an open aqueduct prior to ETV (19) could be identified. Mean ER and FOHR were reduced by 0.03 and 0.05 , respectively. Maintained open (flow void on postop $\mathrm{MRI}$ ) or perforation could successfully be carried out during endoscopic surgery in 44 patients (79\%). The disproportionate increase of head circumference abated in $79.4 \%$ of patients. New shunt insertion occurred in 16 patients (27.5\%). Intraoperatively upward CSF flow was detected in all cases. Statistical analyses (ANOVA) showed significant results for unprotected education, postoperative ER and FOHR but not for open stoma.

Conclusion: The identification of flow through the stoma on postoperative MRI seems to be a necessary but not sufficient condition for ETV success. In our study, ventricular volumes were used as parameters to determine success rates as well as unprotected education. Furthermore, enabling upward CSF flow driven by inspiration seems crucial for successful ETV.

\section{Introduction:}

Paediatric neurosurgeons have been trying to develop and apply effective hydrocephalus (HC) therapies for decades (Paulsen et al., 2016). It has been shown that the first step in the decision-making process for the initial HC therapy is crucial for follow-up surgeries, i.e., either shunt or neuroendoscopic approaches or their combination (Reddy et al., 2014; Bock et al., 2018a). 
ETV is a widely accepted first-line option for treating $\mathrm{HC}$ by opening obstructed ventricular outflow structures. Previously, when ETV procedures were first applied, a disabled or closed aqueduct was proposed. Nowadays, neuroendoscopy is encouraged even in cases with open aqueduct requiring downward and forward bowing of the floor of the $3^{\text {rd }}$ ventricle and the lamina terminalis, respectively (Al-Hakim et al., 2019). After the ETV success score (ETVSS) was developed by Kulkarni et al. (Kulkarni et al., 2010; Foley et al., 2017), the main parameters of the score - infectious or posthemorrhagic causes of ventricle enlargement, age of the patients and tumour diagnosis count - were used to determine the prognosis of the procedure. The score does not assess the time course of the disease, but some of the diagnoses used are correlated with conatal beginning and chronic behavior. To increase the success score, many neurosurgeons execute additional choroid plexus (CP) cauterization (Riva-Cambrin et al., 2019) (Kulkarni et al., 2018), despite the many known essential functions of the CP (Spector et al., 2015).

$\mathrm{CP}$ has a high blood perfusion of $5 \mathrm{mg} / \mathrm{ml} / \mathrm{min}$ comparable to the kidney cortex. Thus, it provides a high-capacity ultrafiltration, secretion and reabsorption feature that is underlined by the high expression of aquaporin-1 (AQP-1). AQP-1 is one of the two molecules in the CNS localized in the main bidirectional water pores of the brain. Moreover the secretion of vesicular mRNA (Spaull et al., 2019) and nutritional factors such as vitamin C into the CSF is facilitated by the CP. It also harbors a unique folate transporter system (Grapp et al., 2013). Dysfunction or genetically caused decrease of these folate transporter leads to the detrimental sequelae of cerebral folate deficiency. One of the most important features of $\mathrm{CP}$ is amyloid- $ß$ recycling and waste clearance. Long-term consequences of $C P$ cauterization (CPC) for children are not known (Spector et al., 2015). It is therefore important to obtain more knowledge about CSF dynamics and the resorptive capacity following ETV procedures for prospective patient stratification and individual therapy.

Many researchers have examined the potential of the ETVSS and its prognostic values. Regarding a sufficiently long follow-up interval, many authors have examined the relevance and acuity of the score, while others have described ETV procedures, which failed despite a high success score (Gianaris et al., 2017). The details of the procedure with visible "naked" basilar artery (BA) and the opening of the Liliequist membranes (LM) as regular situs have been addressed (Mortazavi et al., 2014; Filho et al., 2021), but the success rate of ETV over more than 5 years has not exceeded $70-80 \%$. Regarding insufficient cases, visible membranes 
have been discussed, or disparities in reabsorption of the CSF postulated (Kehler and Gliemroth, 2003). Most of the reports have excluded any confounding prospective value for ventricular size parameters or signs indicating low reabsorption of CSF (Coulter et al., 2020). It is widely known that even in successful ETV with regular outcome parameters, ventricular size does not truly matter, and many children who have undergone ETV grow up to have severely enlarged ventricles. MRI images are commonly assessed annually to exclude the reclosure of the stoma. Recent data from prospective cohort studies have demonstrated that the safety and efficacy of ETV compared to ventriculoperitoneal shunt diversion has been proven to be significant (Pande et al., 2021). The therapeutic efficacy of ETV was similar, but the complication rates of VPS were higher to those of ETV.

Therefore, it is necessary to analyse data with the focus on ETV failures, which cannot be easily explained based on our current knowledge. For patients with obstruction of the CSF compartments, creating a whole into the pathway to bypass the occlusion must be sufficiently working.

Considering recently reported experiences regarding inspiration-modulated and cardiactriggered CSF flow (Dreha-Kulaczewski et al., 2015, 2017), (Takizawa et al., 2017) motion has been observed in the spinal-to-rostral direction in healthy volunteers. Such motion can also be observed after the successful opening of the stoma intraoperatively. We have therefore postulated and demonstrated a CSF trapping mechanism for cases of obstructions (Ludwig et al., 2020). MRI scans of spontaneously breathing young adults could be used to elucidate the underlying physiological mechanism, as described previously (Dreha-Kulaczewski et al., 2015). In summary, real-time MRI scans could show slow but sustainable CSF motion from the spine to rostral part of the brain, whereas cardiac modulation enables fast but unsustainable oscillatory pulsation of CSF through the aqueduct or opened stoma. This observation has often been investigated or confirmed by several authors and has been accepted in recent literature (Takizawa et al., 2017; Rasmussen et al., 2021).

Therefore, the main objective of the present study was to determine the implications of the ETV success score for long-term follow-up with respect to imaging details in pre- and postoperative MRI scans together with intraoperative details, ventricular size, clinical data and educational milestones for any conflicting parameters. 


\section{Patients and Methods}

We conducted a prospective study on 58 children suffering from $\mathrm{HC}$ in a university medical center between 2000 and 2020. The patients were recruited using our institutional HC registry (Bock et al., 2018b). The diagnoses varied between pure aqueductal stenosis, tectal or ventricular tumour obstruction, arachnoid cysts and Dandy Walker malformation showing different grades of ventricle outlet obstruction. Some patients with normal pressure hydrocephalus (NPH) $(\mathrm{N}=4)$ were treated by ETV as well. Ten patients had received a VPS before ETV, and the indications for ETV were shunt failure together with signs of trapping and ventricular enlargement. All patients were hospitalized in a neuropaediatric ward, and each patient underwent MRI prior to ETV, intraoperative video documentation and a series of control postoperative MRIs. All penetrations of the floor of the third ventricle were performed using a 2.0-micron laser (Revolix, LisaLaser OHG, Katlenburg, Germany) assisted by neuronavigation, as previous described (Schuhmann et al., 2019). All patients were followed up regularly as outpatients for an average of 4.7 years. Pre- and postoperative head circumferences were measured and ETVSS, open or obstructed aqueduct before neuroendoscopy, spontaneously perforated septum pellucidum, periventricular lucency (PVL) and downward bowing of the bottom of the third ventricle as different signs for the time scale of obstruction were obtained. Ventricular diameters as ER and FOHR were collected preoperatively and at 3 months post-surgery. Success of ETV was defined by complete regression of symptoms and papilledema, the abatement of the disproportionate increase of head circumferences, and reduction of behavioural disturbances. Analysis of MRI parameters comprised flow void signals through the stoma or through the aqueduct. We collected data on social and neuropsychological outcomes in terms of protected and unprotected education. Four patients were measured pre- and postoperatively by real-time MRI for CSF flow studies, in accordance with a previously described protocol (DrehaKulaczewski et al., 2015, 2017).

\section{Real-time phase-contrast flow MRI}

All datasets were acquired on a 3 Tesla scanner (Magnetom Prisma Fit, Siemens Healthcare) using real-time phase-contrast flow MRI based on highly undersampled radial FLASH sequences as described (Unterberger and Holzapfel, 2014), (Joseph et al., 2012), (Dreha- 
Kulaczewski et al., 2015, 2017; Ludwig et al., 2021a) Measurements in sagittal or coronal orientation to the stoma in the floor of the $3^{\text {rd }}$ ventricle were conducted with a 64-channel head coil.

\section{Data Analysis}

Real-time flow MRI datasets were quantitatively analysed using CaFuR software (Fraunhofer Mevis, Bremen, Germany) (Chitiboi et al., 2014), which is designed to accomplish automatic segmentation of flow signals in real-time image series as described before. The manual definition of an initial ROI for the determination of through-plane flow was based on both signal intensities in magnitude images and corresponding phase difference values in velocity maps. Further data processing was performed using MATLAB (Mathworks, Massachusetts, USA), including net flow calculation and data visualization.

Statistical analyses, including ANOVA, and the development of graphics were completed with Statistica $^{\text {TM }}$ (TIBCO Software Inc. Palo Alto, CA 94304 USA).

\section{Results}

The age of the infants and adolescents at the time of endoscopic treatment varied between newborns and 18 years (mean 7.76 yrs.). The diagnoses included aqueductal stenosis (11), tectal or ventricular tumour obstruction (22), Dandy Walker malformation (9), arachnoid cysts (4), NPH (4) and posthemorrhagic HC (5) (PHHC) (Table 1). Seven children were preterm, and 11 children were below 12 months old.

\section{Preop MR-imaging parameters}

The parameters bowing of the $3^{\text {rd }}$ ventricle floor were seen in $72.4 \%$ of the images, periventricular lucency in $37.9 \%$ and septal perforations in $48.3 \%$ (s. Fig 4). A significant correlation was observed between bowing and PVL. Septal perforations were significantly correlated with preoperative ventricular sizes (Table 3). The aqueduct was classified as open 
in $29.3 \%$ of patients before ETV (Table 3). These preoperative parameters were not stratified singificantly based on for failure and educational results.

\section{Intraoperative observations}

During all ETVs, clear CSF-upward movement could be identified endoscipically, following a typical pattern of cardiac pulsating movement superimposed by a strong inspiratory flow that typically moves the rims of the created stoma and fragmentary particles (Fig. 5 and Video 1, supplemental data), thus indicating net upward flow. The procedure was completed by confirmation of a visible naked BA. Liliequist membranes were opened if necessary for unhindered upward CSF flow (Table 1).

\section{Postoperative clinical and MR-imaging parameters}

ER I (mean 0.49) and FOHR I (mean 0.54) were reduced by mean 0.04 and 0.06 and a flow void could be observed in $79 \%$ of patients 3 months postoperatively. In 11 patients the aqueduct which appeared obstructed on pre-op MRI by missing flow void showed a flow void on postop imaging. The disproportionate increase of head circumference abated in $79.4 \%$ of patients during the follow up. Shunt insertion was carried out in 16 patients, indicated in cases of developmental delay, prolonged subcutaneous CSF collection or persistent papilledema. ETV had to be repeated in 2 patients due to missing flow void postoperatively. The mean interval for shunt implantation after ETV was 97 days (max=18 months). In patients older than 1 year of age, the success rate increased to $77 \%$, compared to a success rate of $74 \%$ in all patients. Statistical analysis revealed unprotected educational outcome (77.6\%) and ETV failure being significantly $\mathrm{p}<0.05$ (Table 4 ) dependent on the preoperative and postoperative ventricular scores but not dependent on the delta indices (Fig. 3).

\section{Real-time MRI}

Qualitative evaluation of the magnitude images of 3 patients showed distinct CSF flow through the stoma in one of them. In the second patient only a faint flow signal could be observed in the Monroi foramina (s. Fig. 1). The study in the third patient did not allow for unambiguous assessment of flow, presumably due to the stoma being located outside the 
measurement slice.

\section{Outcome}

Protected education in kindergarten and school was necessary for 13 children (22.4\%). The rate related to successful ETV without further shunt dependency was 8/42 (19\%). Protected education was significantly correlated with ventricular volumetry, ETVSS and age $(p<0.05)$. ETVSS was not significantly correlated with terminated elevation of head circumference, ventricular volumes, or postoperative open stoma $(p<0.05)$ (Table 4$)$.

\section{Discussion}

Current research has increasingly challenged the prevalent concepts of CSF dynamics. Despite of mounting evidence, $\mathrm{HC}$ as a disturbance of certain parts of the glymphatic system is still not widely accepted (Ludwig et al., 2021b). HC has been categorized into obstructive or communicating types according to the historical classifications established by Dandy (Dandy, 1919). The current literature identifies CSF reabsorption in addition to Pacchioni granulations by the $\mathrm{CP}$ itself. A second pathway leads from the basal cisterns, following the penetrating arterial vessels towards the venous site of the Virchow Robin compartment into lymphatic vessels of the meninges and cervical downstream (Nakada et al., 2017; Nakada and Kwee, 2019). Facilitated by insights into the aquaporin system, CSF reabsorption by differentially located expression on cell membranes of the ependymal and astrocytic periventricular networks has been identified. It can be considered that different pathways exist in parallel depending on the disease and pathophysiology. We have presented a significant upward CSF flow initiated by forced inspiration. Simultaneously venous blood is pooled from intracranial to thoracic large venous vessels, which are balanced by upward CSF flow in accordance with the Monro Kelly doctrine. The new concept has helped neurosurgeons to interpret the intraoperative phenomenon, which they routinely observe during the opening of the floor of the $3^{\text {rd }}$ ventricle when CSF clearly moves upwards (Bock et al., 2019; Ludwig et al., 2020). This observation could not be explained for a long time. Traditionally, it was assumed that CSF is mainly secreted by the $\mathrm{CP}$ and distributed by bulk flow into the major pathways. It then mixes and diffuses towards the arachnoid spaces of the lower posterior fossa, and finally reaches 
the cerebral subarachnoid spaces and meningeal venous and lymphatic vessels. This interpretation extended the use of ETV with the adjuvant use of CPC, thereby reducing CSF secretion and loading to be consistent with the expected malabsorption. Previous findings related to the use of CPC to increase the success rates of ETV seem to support this approach (Dewan et al., 2018).

It is important to consider recent meta-analyses that have shown the slight superiority of ETV compared to VPS therapy with respect to safety and complications (Pande et al., 2021). It is also important to consider that approximately $30 \%$ of cases cannot be treated sufficiently by ETV despite a high preoperative success score

Measuring outcome parameters of ETV can be conducted by counting those cases in which further shunt therapy was needed to sufficiently treat clinical symptoms, increasing head circumference and reaching developmental milestones. Finally, educational performance in kindergarten and school is an important stratifying parameter. In our study, the prospective ETV success rate was $71 \%$ (mean), and $81 \%$ of the patients with successful ETV yielded unprotected education. The main parameter for the success of ETV was not dependent on an open stoma in postoperative MRI or on delta ER or delta FOHR, as expected. The remnant postoperative ventricular morphometric indices ER and FOHR were highly significant. This implies that in addition to opening all obstructions within the CSF pathways, necessary access to the different elements of its absorption should exist. ETV seems to have a higher failure rate if this is not sufficiently provided. Two different main principles for absorption exist. CSF access to the subarachnoid spaces could be obtained by an open stoma, and an important element of the resorptive capacity should function sufficiently. This has been discussed by Rasmussen et al. as well as by our group (Ludwig et al., 2021b) (Rasmussen et al., 2021). To enable this access, CSF must reach the absorbing network by entering the subarachnoid cisterns and spaces to further follow along the penetrating vessels into the Virchow Robin spaces (Iliff et al., 2012),(Shetty and Zanirati, 2020). However, the pressure gradient between subarachnoid spaces and the Virchow Robin space is not sufficient to induce fluid flow in the pericapillary spaces (Martinac et al., 2021). Therefore, the second part of the system, previously called the "minor pathway" (Oi and DiRocco, 2006), enables access to the interstitial fluid compartment by peri-ependymal pathways into the subependymal interstitial fluid system, thus reaching the Virchow Robin spaces as well (Bulat et al., 2008; Bulat and Klarica, 2011; Casaca-Carreira et al., 2018; Nakada and Kwee, 2019) and serving as a preload 
volume. The large glial astrocytic compartment of this system equipped with AQP4 pores requires sufficient fluid supply as "preloading" volume and to enable peristaltic fluid propagation along penetrating pial vessels and capillaries. This perivascular part of the CSF volume might come in sufficient contact with the glial system after successful ETV and thereby enable upward flow. If this astrocytic and interstitial system is not able to fulfil these requirements on the microscale, disturbances of fluid absorption could be expected. The preliminary results of the real-time MRI of CSF movements, suggest that a successful ETV was associated with marked inspiratory CSF flow whether through the stoma itself into the $3^{\text {rd }}$ ventricle or through the Monroi foramina into the lateral ventricles (Dreha-Kulaczewski et al., 2015) (Dreha-Kulaczewski et al., 2017) (Casaca-Carreira et al., 2018), (Whish et al., 2015). From this point of view, it seems important to establish a sufficient parenchymal thickness by ventricular decompression. The importance of sufficient postoperative morphometric indices might be one of the reasons some reports indicate an increased success rate of ETV by applying a routine lumbar drain for multiple days (Watkins et al., 2017).

\section{Conclusion}

Current research has increasingly challenged the prevalent concepts of CSF dynamics. HC, even being purely obstructive, might be one of the factors which disturb the complex glymphatic system. We have added our view of respiration-driven CSF upwards dynamics and the occurrence of trapping and valve mechanisms, which can explain many results of $\mathrm{HC}$ therapy. Our results after ETV showed that despite open stoma on postoperative MRI, successful outcomes and unprotected education depend on the postoperative achievable ventricular size. Therefore, according to our data, open stoma after ETV seems to be a necessary but not sufficient condition. Preloading access of surplus CSF to a patent astrocytic glymphatic system appears to be the second crucial condition.

Ethical approval: Ethical review committee: University Medical Center Ethical Board Approval number: 12/9/17 
Tables and Figures:

\begin{tabular}{|l|l|l|}
\hline Cause & $\mathbf{N}$ & $\%$ \\
\hline OH & 54 & 93.10 \\
\hline LH & 4 & 6.90 \\
\hline Tumour & 22 & 37.93 \\
\hline AS & 11 & 18.97 \\
\hline Malformation & 9 & 15.52 \\
\hline PHHC & 5 & 8.62 \\
\hline NPH & 4 & 6.90 \\
\hline Arachnoid cyst & 4 & 6.90 \\
\hline Other & 3 & 5.17 \\
\hline
\end{tabular}

Table 1: Overview of the pathologies and causes of ETV, obstructive hydrocephalus $(\mathrm{OH})$, loculated hydrocephalus (LH), and aqueductal stenosis (AS). 


\begin{tabular}{|c|c|c|c|c|c|c|}
\hline & & Min & Max & Mean & $\mathbf{N}$ & $\%$ \\
\hline \multirow[t]{7}{*}{ Preoperative } & PVL & & & & 22 & 37.93 \\
\hline & Bowing & & & & 42 & 72.41 \\
\hline & Open aq pre & & & & 17 & 29.3 \\
\hline & $\begin{array}{l}\text { Septal } \\
\text { perforation }\end{array}$ & & & & 28 & 48.28 \\
\hline & ETVSS & 10 & 90 & 71 & & \\
\hline & Age & 0.1 & 18 & 7.76 & & \\
\hline & Preterm & & & & 7 & 12.0 \\
\hline \multirow[t]{3}{*}{ Intraoperation } & \multicolumn{2}{|l|}{ Upward flow } & & & 58 & 100.00 \\
\hline & Naked BA & & & & 52 & 89.66 \\
\hline & Opened LM & & & & 27 & 46.55 \\
\hline \multirow[t]{15}{*}{ Postoperation } & \multicolumn{2}{|l|}{ Open stoma MRI } & & & $37 / 48$ & 79 \\
\hline & Open aq post & & & & $11 / 48$ & 22.9 \\
\hline & Head circ. stop & & & & $31 / 39$ & 79.4 \\
\hline & FOHR I & 0.36 & 0.77 & 0.54 & & \\
\hline & FOHR II & 0.34 & 0.71 & 0.51 & & \\
\hline & Delta-FOHR & 0 & 1.2 & 0.08 & & \\
\hline & Evans R I & 0.31 & 0.76 & 0.49 & & \\
\hline & Evans R II & 0.31 & 0.7 & 0.47 & & \\
\hline & Delta-Evans R & 0.06 & 0.14 & 0.03 & & \\
\hline & VPS pre & & & & $09 / 58$ & 15.5 \\
\hline & VPS post & & & & $25 / 58$ & 43.1 \\
\hline & \multicolumn{2}{|c|}{ Protected education } & & & $13 / 58$ & 22.4 \\
\hline & \multicolumn{2}{|c|}{$\begin{array}{l}\text { Protected ed/successful } \\
\text { ETV }\end{array}$} & & & $08 / 42$ & 19.0 \\
\hline & \multicolumn{2}{|l|}{ ETV failure } & & & $16 / 58$ & 27.5 \\
\hline & \multicolumn{2}{|c|}{ ETV failure $>1 \mathrm{yr}$ of age } & & & $11 / 47$ & 23.4 \\
\hline
\end{tabular}

Table 2: Overview of the results of all parameters: periventricular lucency (PVL) 


\begin{tabular}{|l|l|l|}
\hline & PVL & Septal Perforation \\
\hline $\mathbf{3}^{\text {rd }}$ ventr. bowing & 0.012 & no \\
\hline Evans R I & no & 0.001 \\
\hline FOHR I & no & 0.001 \\
\hline
\end{tabular}

Table 3: Statistically significant $(p<0.05)$ correlations of preoperative imaging results and significant $(p<0.05)$ periventricular lucency $(P V L)$.

\begin{tabular}{|l|l|l|l|l|l|l|}
\hline & ER II & FOHR II & Delta ER & Delta & Age & ETVSS \\
\hline Education & 0.022 & 0.022 & no & no & 0.001 & $<0.001$ \\
\hline Failure & 0.04 & 0.04 & no & no & 0.026 & 0.002 \\
\hline Open stoma & no & no & no & no & 0.017 & no \\
\hline Head C stop & no & no & 0.001 & 0.001 & no & no \\
\hline Bowing & no & no & no & no & no & no \\
\hline Naked BA & no & no & no & no & no & no \\
\hline Liliequist M. & no & no & no & no & no & no \\
\hline
\end{tabular}

Table 4: Overview of statistical parameter analysis of postoperative $p$ values, significant $\mathrm{p}<0.05$ 

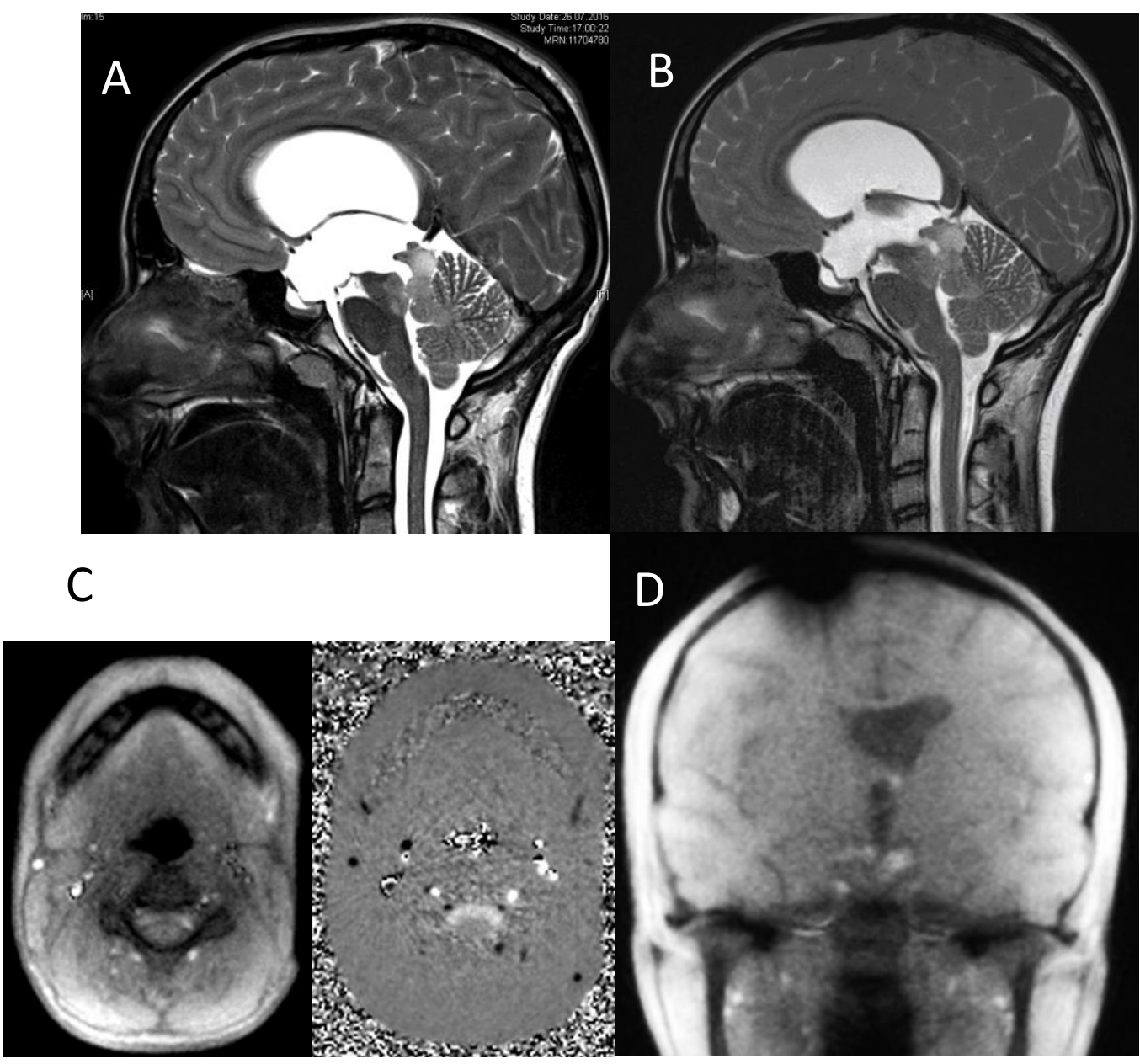

Fig. 1: Preop MRI (A) showing tectal tumour stenosis in a 15 years old male, widened ventricles with PVL, bowing of floor of third ventricle and lamina terminalis; ER: 0.44; FOHR 0.53. (B) 3 months later still hydrocephalic despite reduced PVL and reduced ER 0.3 and FOHR 0.38. Real time MRI with sparsely flow signals not crossing the level of the Monroi foramen despite visible venous downward flow and CSF flow upwards at spinal level C3 (C) during forced inspiration, magnitude image (right) and phase contrast velocity map (left). Magnitude image displays flow (CSF and epidural veins) in subarachnoid space qualitatively. The pc image indicates upward flow of CSF (bright) and simultaneous downward flow (dark) in epidural veins. 


\section{pre ETV}

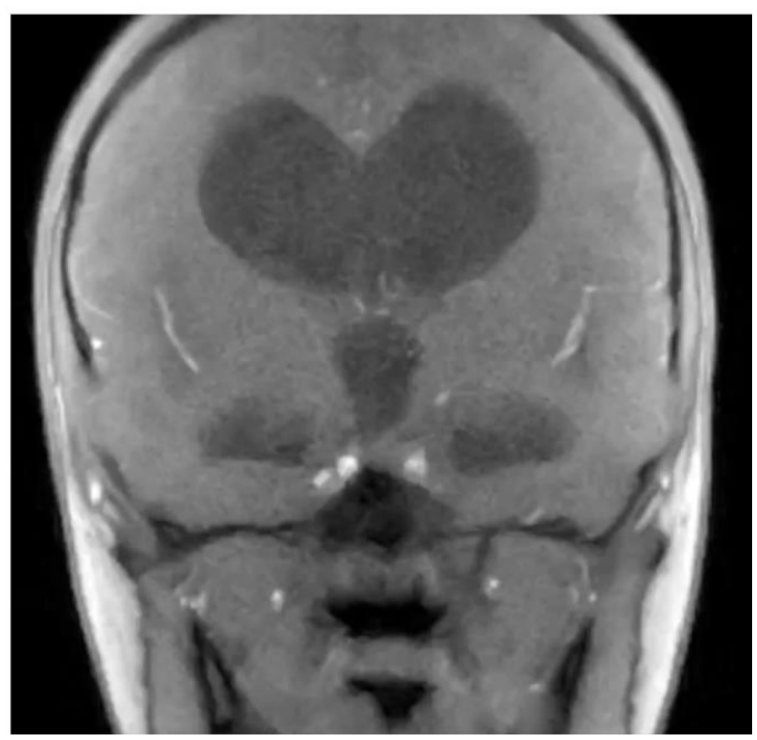

FOHR 0.54

\section{post ETV}

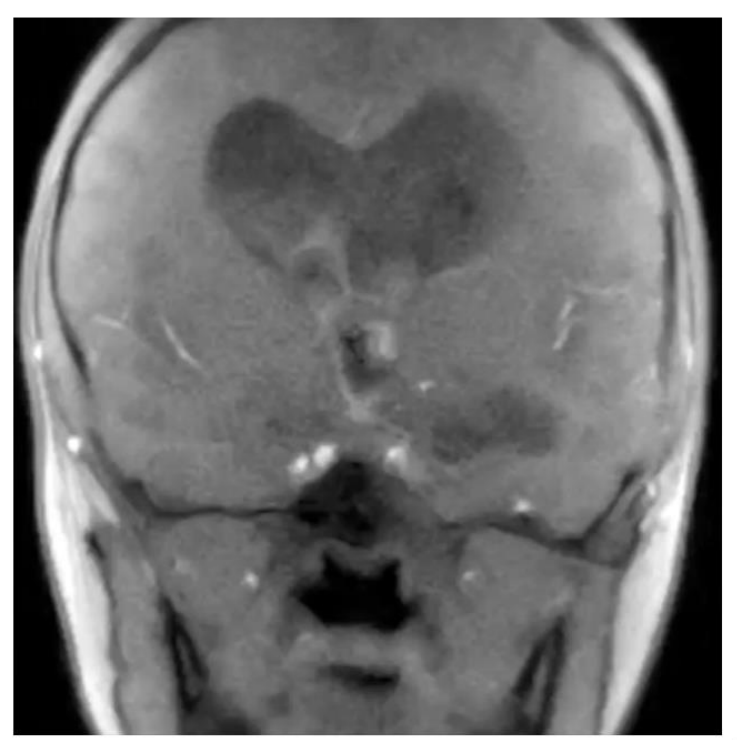

FOHR 0.47

Fig. 2: Missing upward CSF flow before (left) and visible flow void inside the $3^{\text {rd }}$ ventricle passing the Monroi foramen (right) after successful ETV, reduced FOHR 3 months after ETV

Vertical Bars: $0.95 \mathrm{Cl} ; \mathrm{p}=, 04305$

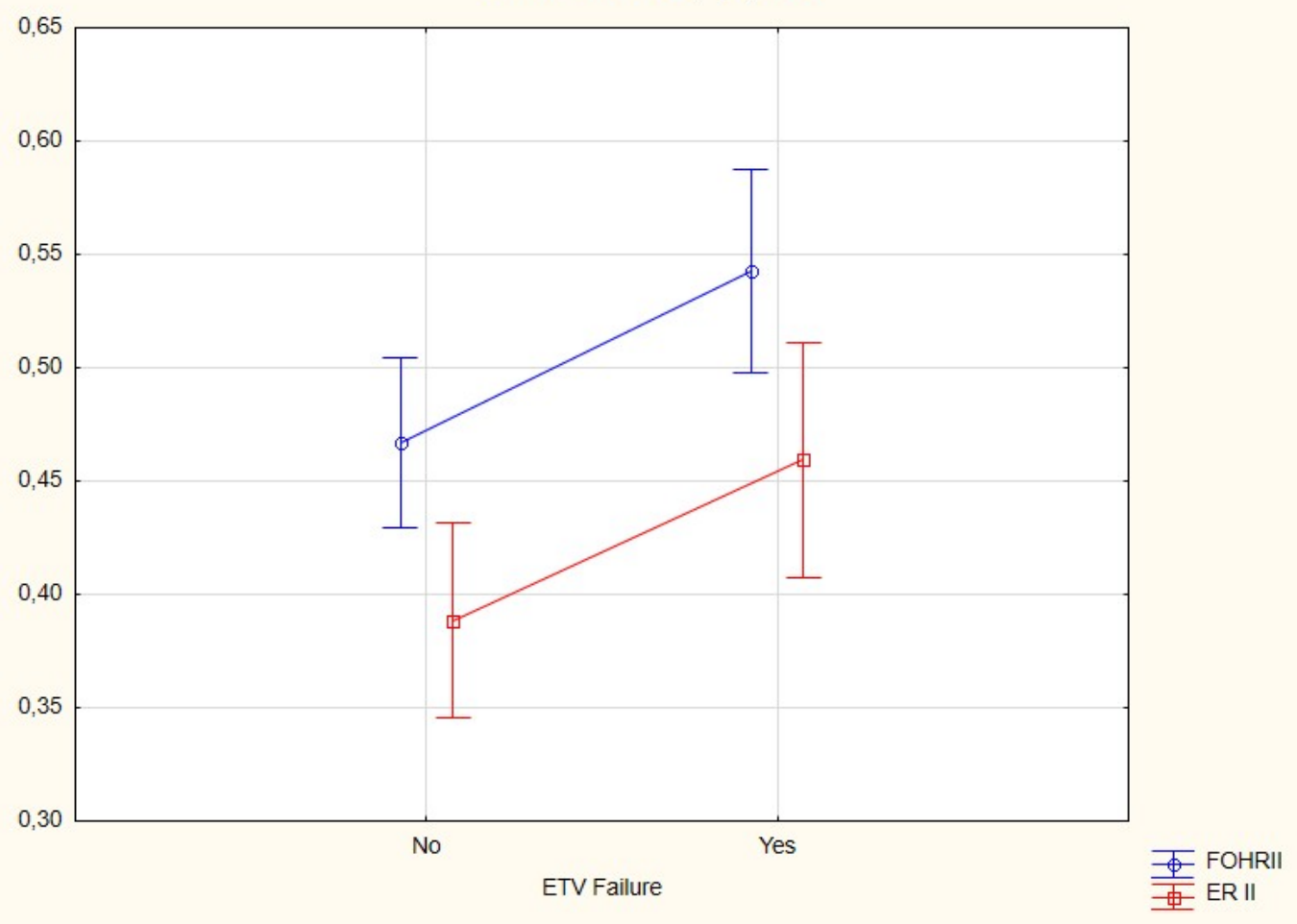


Figure 3: Significant correlation between postoperative ventricular sizes and ETV failure. Delta indices were not significantly correlated $(N=48, p=0.04)$.

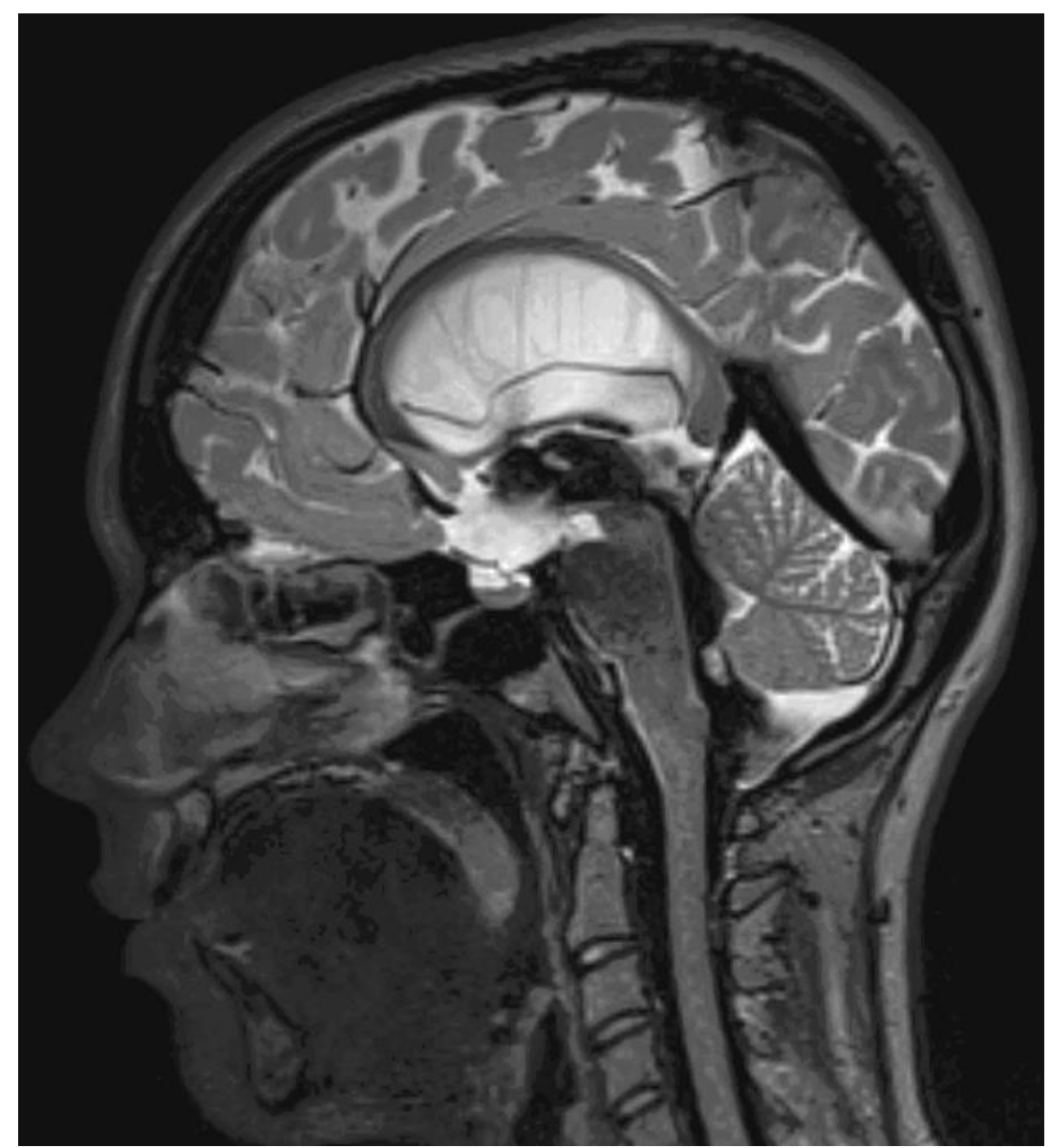

Fig. 4: Bowing floor of the $3^{\text {rd }}$ ventricle as a sign of a pressure gradient, open hyperdynamic CSF flow through the aqueduct and parachute sign in a patient with NPH 


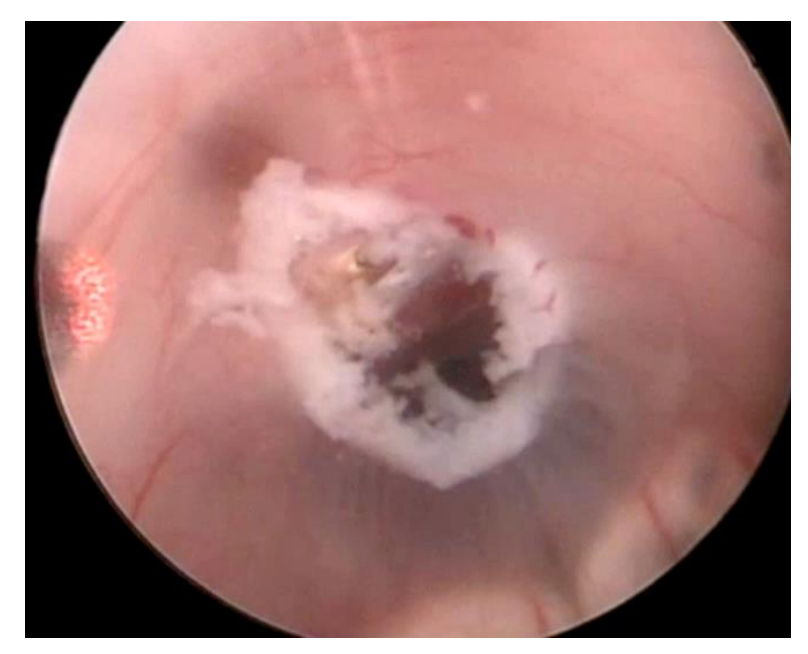

Fig. 5: Typical aspect on the opened floor of the $3^{\text {rd }}$ ventricle with upward CSF flow, indicated by stoma rims moving upward 


\section{References}

Al-Hakim S, Schaumann A, Tietze A, Schulz M, Thomale UW. 2019. Endoscopic third ventriculostomy in children with third ventricular pressure gradient and open ventricular outlets on MRI. Child's Nervous System 35:2319-2326.

Bock HC, Dreha-Kulaczewski SF, Alaid A, Gärtner J, Ludwig HC. 2019. Upward movement of cerebrospinal fluid in obstructive hydrocephalus-revision of an old concept. Child's Nervous System [Internet] 35:833-841. Available from: https://link.springer.com/content/pdf/10.1007\%2Fs00381-019-04119-x.pdf

Bock HC, Feldmann J, Ludwig H-C. 2018a. Early surgical management and long-term surgical outcome for intraventricular hemorrhage-related posthemorrhagic hydrocephalus in shunt-treated premature infants. Journal of neurosurgery Pediatrics 22:1-7.

Bock HC, Kanzler M, Thomale U-W, Ludwig H-C. 2018b. Implementing a digital real-time Hydrocephalus and Shunt Registry to evaluate contemporary pattern of care and surgical outcome in pediatric hydrocephalus. Child's Nervous System 34:457-464.

Bulat M, Klarica M. 2011. Recent insights into a new hydrodynamics of the cerebrospinal fluid. Brain Research Reviews 65:99-112.

Bulat M, Lupret V, Ore\{kovic D, Klarica M. 2008. Transventricular and Transpial Absorption of Cerebrospinal Fluid into Cerebral Microvessels. Coll Antropol 32:43-50.

Casaca-Carreira J, Temel Y, Hescham S-A, Jahanshahi A. 2018. Transependymal Cerebrospinal Fluid Flow: Opportunity for Drug Delivery? Mol Neurobiol 55:2780-2788.

Chitiboi T, Hennemuth A, Tautz L, Huellebrand M, Frahm J, Linsen L, Hahn H. 2014. ContextBased Segmentation and Analysis of Multi-Cycle Real-Time Cardiac MRI. 2014 leee 11th Int Symposium Biomed Imaging Isbi:943-946.

Coulter IC, Kulkarni AV, Constantini S, Investigators IIHS, Sgouros S, Leitner Y, Kestle JR, Cochrane DD, Choux M, Gjerris F, Sherer A, Akalan N, Bilginer B, Navarro R, Vujotic L, Haberl H, Thomale U-W, Zúccaro G, Jaimovitch R, Frim D, Loftis L, Swift DM, Robertson B, Gargan L, Bognar L, Novák L, Cseke G, Cama A, Ravegnani GM, Preuss M, Schroeder HW, Fritsch M, Baldauf J, Mandera M, Luszawski J, Skorupka P, Mallucci C, Williams D, Zakrzewski K, Nowoslawska E, Srivastava C, Mahapatra AK, Kumar R, Sahu RN, Melikian AG, Korshunov A, Galstyan A, Suri A, Gupta D, Grotenhuis JA, Lindert EJ van, Val JA da C, Rocco CD, Tamburrini G, Zymberg ST, Cavalheiro S, Jie M, Feng J, Friedman O, Rajmohamed N, Roszkowski M, Barszcz S, Jallo G, Pincus DW, Richter B, Mehdorn HM, Schultka S, Ribaupierre S de, Thompson D, Gatscher S, Wagner W, Koch D, Cipri S, Zaccone C, McDonald P. 2020. Cranial and ventricular size following shunting or endoscopic third ventriculostomy (ETV) in infants with aqueductal stenosis: further 
insights from the International Infant Hydrocephalus Study (IIHS). Child's Nervous System 36:1407-1414.

Dandy WE. 1919. Experimental Hydrocephalus. Ann Surg 70:129-142.

Dewan MC, Lim J, Gannon SR, Heaner D, Davis MC, Vaughn B, Chern JJ, Rocque BG, Klimo P, Wellons JC, Naftel RP. 2018. Comparison of hydrocephalus metrics between infants successfully treated with endoscopic third ventriculostomy with choroid plexus cauterization and those treated with a ventriculoperitoneal shunt: a multicenter matched-cohort analysis. Journal of neurosurgery Pediatrics 21:339-345.

Dreha-Kulaczewski S, Joseph AA, Merboldt K-D, Ludwig H-C, Gärtner J, Frahm J. 2015. Inspiration is the major regulator of human CSF flow. The Journal of neuroscience : the official journal of the Society for Neuroscience 35:2485-2491.

Dreha-Kulaczewski S, Joseph AA, Merboldt K-D, Ludwig H-C, Gärtner J, Frahm J. 2017. Identification of the Upward Movement of Human Cerebrospinal Fluid In Vivo and its Relation to the Brain Venous System. Journal of Neuroscience 37:2395-2402.

Filho JA da CV, Gusmão SN da S, Furtado LMF, Filho G de MM, Maciel FLA. 2021. The role of the Liliequist membrane in the third ventriculostomy. Neurosurg Rev:1-11.

Foley RW, Ndoro S, Crimmins D, Caird J. 2017. Is the endoscopic third ventriculostomy success score an appropriate tool to inform clinical decision-making? British journal of neurosurgery 31:314-319.

Gianaris TJ, Nazar R, Middlebrook E, Gonda DD, Jea A, Fulkerson DH. 2017. Failure of ETV in patients with the highest ETV success scores. Journal of neurosurgery Pediatrics 20:225231.

Grapp M, Wrede A, Schweizer M, Huewel S, Galla H-J, Snaidero N, Simons M, Bueckers J, Low PS, Urlaub H, Gaertner J, Steinfeld R. 2013. Choroid plexus transcytosis and exosome shuttling deliver folate into brain parenchyma. Nature Communications 4.

Iliff JJ, Wang M, Liao Y, Plogg BA, Peng W, Gundersen GA, Benveniste H, Vates GE, Deane R, Goldman SA, Nagelhus EA, Nedergaard M. 2012. A Paravascular Pathway Facilitates CSF Flow Through the Brain Parenchyma and the Clearance of Interstitial Solutes, Including Amyloid $\beta$. Sci Transl Med 4:147ra111-147ra111.

Joseph AA, Merboldt K, Voit D, Zhang S, Uecker M, Lotz J, Frahm J. 2012. Real-time phasecontrast MRI of cardiovascular blood flow using undersampled radial fast low-angle shot and nonlinear inverse reconstruction. Nmr Biomed 25:917-924.

Kehler U, Gliemroth J. 2003. Extraventricular intracisternal obstructive hydrocephalus--a hypothesis to explain successful 3rd ventriculostomy in communicating hydrocephalus. Pediatric neurosurgery 38:98-101.

Kulkarni AV, Drake JM, Kestle JRW, Mallucci CL, Sgouros S, Constantini S, Group CPNS. 2010. Predicting who will benefit from endoscopic third ventriculostomy compared with shunt 
insertion in childhood hydrocephalus using the ETV Success Score. Journal of neurosurgery Pediatrics 6:310-315.

Kulkarni AV, Riva-Cambrin J, Rozzelle CJ, Naftel RP, Alvey JS, Reeder RW, Holubkov R, Browd SR, Cochrane DD, Limbrick DD, Simon TD, Tamber M, Wellons JC, Whitehead WE, Kestle JRW. 2018. Endoscopic third ventriculostomy and choroid plexus cauterization in infant hydrocephalus: a prospective study by the Hydrocephalus Clinical Research Network. Journal of neurosurgery Pediatrics 21:214-223.

Ludwig H, Bock H, Gärtner J, Schiller S, Frahm J, Dreha-Kulaczewski S. 2021a. Hydrocephalus Revisited: New Insights into Dynamics of Neurofluids on Macro- and Microscales. Neuropediatrics 52:233-241.

Ludwig HC, Bock HC, Dreha-Kulaczewski S. 2020. CSF upward flow during neuroendoscopy of obstructive hydrocephalus: What is the implication for ETV success? Childs Nerv System 34:995-1094.

Ludwig HC, Dreha-Kulaczewski S, Bock HC. 2021b. Neurofluids-Deep inspiration, cilia and preloading of the astrocytic network. J Neurosci Res 99:2804-2821.

Martinac AD, Fletcher DF, Bilston LE. 2021. Phase offset between arterial pulsations and subarachnoid space pressure fluctuations are unlikely to drive periarterial cerebrospinal fluid flow. Biomech Model Mechan:1-16.

Mortazavi MM, Rizq F, Harmon O, Adeeb N, Gorjian M, Hose N, Modammadirad E, Taghavi $P$, Rocque BG, Tubbs RS. 2014. Anatomical variations and neurosurgical significance of Liliequist's membrane. Child's Nervous System 31:15-28.

Nakada T, Kwee I, Igarashi H, Suzuki Y. 2017. Aquaporin-4 Functionality and Virchow-Robin Space Water Dynamics: Physiological Model for Neurovascular Coupling and Glymphatic Flow. International Journal of Molecular Sciences 18:1798-14.

Nakada T, Kwee IL. 2019. Fluid Dynamics Inside the Brain Barrier: Current Concept of Interstitial Flow, Glymphatic Flow, and Cerebrospinal Fluid Circulation in the Brain. The Neuroscientist [Internet] 25:155-166. Available from:

https://www.ncbi.nlm.nih.gov/pmc/articles/PMC6416706/pdf/10.1177_1073858418775 027.pdf

Oi S, DiRocco C. 2006. Proposal of "evolution theory in cerebrospinal fluid dynamics" and minor pathway hydrocephalus in developing immature brain. Child's Nervous System 22:662-669.

Pande A, Lamba N, Mammi M, Gebrehiwet P, Trenary A, Doucette J, Papatheodorou S, Bunevicius A, Smith TR, Mekary RA. 2021. Endoscopic third ventriculostomy versus ventriculoperitoneal shunt in pediatric and adult population: a systematic review and meta-analysis. Neurosurg Rev 44:1227-1241.

Paulsen AH, Due-Tønnessen BJ, Lundar T, Lindegaard K-F. 2016. Cerebrospinal fluid (CSF) shunting and ventriculocisternostomy (ETV) in 400 pediatric patients. Shifts in 
understanding, diagnostics, case-mix, and surgical management during half a century. Child's Nervous System:1-10.

Rasmussen MK, Mestre H, Nedergaard M. 2021. Fluid Transport in the Brain. Physiol Rev.

Reddy GK, Bollam P, Caldito G. 2014. Long-Term Outcomes of Ventriculoperitoneal Shunt Surgery in Patients with Hydrocephalus. World neurosurgery 81:404-410.

Riva-Cambrin J, Kestle JRW, Rozzelle CJ, Naftel RP, Alvey JS, Reeder RW, Holubkov R, Browd SR, Cochrane DD, Limbrick DD, Shannon CN, Simon TD, Tamber MS, Wellons JC, Whitehead WE, Kulkarni AV, Network HCR. 2019. Predictors of success for combined endoscopic third ventriculostomy and choroid plexus cauterization in a North American setting: a Hydrocephalus Clinical Research Network study. Journal of neurosurgery Pediatrics 24:1-11.

Schuhmann MU, Kural C, Lalla L, Ebner FH, Bock C, Ludwig H-C. 2019. Two-Micron Continuous-Wave Laser-Assisted Neuroendoscopy: Clinical Experience of Two Institutions in 524 Procedures. World neurosurgery 122:e81-e88.

Shetty AK, Zanirati G. 2020. The Interstitial System of the Brain in Health and Disease. Aging Dis 11:200-211.

Spaull R, McPherson B, Gialeli A, Clayton A, Uney J, Heep A, Cordero-Llana Ó. 2019. Exosomes populate the cerebrospinal fluid of preterm infants with post-haemorrhagic hydrocephalus. International journal of developmental neuroscience : the official journal of the International Society for Developmental Neuroscience 73:59-65.

Spector R, Snodgrass SR, Johanson CE. 2015. A balanced view of the cerebrospinal fluid composition and functions: Focus on adult humans. Experimental neurology 273:57-68.

Takizawa K, Matsumae M, Sunohara S, Yatsushiro S, Kuroda K. 2017. Characterization of cardiac- and respiratory-driven cerebrospinal fluid motion based on asynchronous phasecontrast magnetic resonance imaging in volunteers. Fluids and Barriers of the CNS 14:2533.

Unterberger MJ, Holzapfel GA. 2014. Advances in the mechanical modeling of filamentous actin and its cross-linked networks on multiple scales. Biomech Model Mechan 13:11551174.

Watkins J, Cabanne M, Miulli D. 2017. Markedly Improved Success Rate of Endoscopically Assisted Third Ventriculostomy Is Achieved by Routine Placement of External Lumbar Drain. J Neurological Surg Reports 78:e71-e76.

Whish S, Dziegielewska KM, Møllgård K, Noor NM, Liddelow SA, Habgood MD, Richardson SJ, Saunders NR. 2015. The inner CSF-brain barrier: developmentally controlled access to the brain via intercellular junctions. Front Neurosci-switz 9:16. 
